University of Nebraska - Lincoln

DigitalCommons@University of Nebraska - Lincoln

Faculty Publications: Agricultural Economics

Agricultural Economics Department

Winter 1-9-2009

\title{
Efficiency in Midwest US Corn Ethanol Plants: A Plant Survey
}

\author{
Richard K. Perrin \\ University of Nebraska-Lincoln, rperrin@unl.edu \\ Nickolas F. Fretes \\ Harvard University,nfretes@fas.harvard.edu \\ Juan P. Sesmero \\ University of Nebraska-Lincoln, juampase@hotmail.com
}

Follow this and additional works at: https://digitalcommons.unl.edu/ageconfacpub

Part of the Agricultural and Resource Economics Commons

Perrin, Richard K.; Fretes, Nickolas F.; and Sesmero, Juan P., "Efficiency in Midwest US Corn Ethanol Plants: A Plant Survey" (2009). Faculty Publications: Agricultural Economics. 86.

https://digitalcommons.unl.edu/ageconfacpub/86

This Article is brought to you for free and open access by the Agricultural Economics Department at DigitalCommons@University of Nebraska - Lincoln. It has been accepted for inclusion in Faculty Publications: Agricultural Economics by an authorized administrator of DigitalCommons@University of Nebraska - Lincoln. 


\title{
Efficiency in Midwest US Corn Ethanol Plants: A Plant Survey
}

\author{
Richard K. Perrin, Nickolas F. Fretes, and Juan Pablo Sesmero
}

Department of Agricultural Economics, University of Nebraska-Lincoln, Lincoln, NE 68583, USA

Corresponding author - R. K. Perrin, tel 402 472-9818, fax 402 472-3460, email rperrin@unl.edu

\begin{abstract}
Continuation of policy support for the US corn ethanol industry is being debated due to doubts about the greenhouse gas effects of the industry and the effects of the industry on food prices. Yet there is no publicly available data on the economic and technical performance of the current generation of plants, which constitute the overwhelming majority of the industry. This study helps to fill that gap. Seven recently constructed ethanol plants in seven Midwest US states provided details on input requirements and operating costs during 2006 and 2007. Results show that technical performance is substantially better than current estimates available in the literature. Average net operating returns exceeded capital costs during the survey period, but price changes by mid-2008 reduced these margins to near zero. While the economic performance of the industry is currently viable, this study demonstrates that it can be threatened by current price trends, and certainly would be in the absence of current subsidies.
\end{abstract}

Keywords: Corn ethanol efficiency

\section{Introduction}

The role of corn ethanol as a sustainable alternative fuel to gasoline has recently been the subject of much debate. While the scientific community has been debating the net-energy value of ethanol conversion, policymakers have become concerned about the role of the ethanol industry on rising international food prices. As a result, US policy support of corn ethanol is at issue. It is important that policy debates be informed by accurate information about the technical efficiency and economic viability of the industry.

This study reports the results of a recent survey of corn ethanol plants in seven states in the North Central of the US, examining performance during 2006 and 2007. We first characterize the plants surveyed, and then present results on their technical and price efficiencies. We calculate industry shutdown price relationships for corn and oil prices. Next, we estimate the cost of drying distillers grains. Finally, we construct a cost function so as to allow updating the results for changed prices, and we then use it to evaluate the industry's economic viability in mid-2008.

\section{The surveyed plants}

Table 1 presents the characteristics of the plants surveyed for this report. Seven dry-grind ethanol plants were surveyed from north-central Midwest states. The selection criteria for plants to be contacted were as follows. The plant must have started production (or been updated) after mid-2005 with a capacity of about 50,000 million gallons per year or more, so as to represent recent technology. Plants must have a minimum of three quarters of operating data, starting at least one month after the plant opened. Finally, the plants should be located in or near small towns of approximately 10,000 or less, to facilitate companion studies of the impact of the plants on rural communities within the twelve-state North Central region of the US The eighteen plants that met these criteria were contacted, but only seven were persuaded to participate in this research project, because participation entailed a non-trivial effort on their part, and some firms were unwilling to share confidential data.

The seven plants produced an average rate of 53.1 million gallons of denatured ethanol per year, with a range from 42.5 million gallons per year to 88.1 million gallons per year. (All references in this report refer to denatured ethanol. Denatured ethanol must contain between $1.96 \%$ and $4.76 \%$ denaturant, which is usually gasoline. The amounts of denaturant for the sample firms were not obtained.) The period surveyed began in the third quarter of 2006 and lasted until the fourth quarter of 2007 (six consecutive quarters), though not all plants reported results for all quarters. For plants that started up during this period, we include data only for quarters at least one month subsequent to startup. The surveyed plants employed an average of 39.6 employees.

Plants varied in their handling of distillers grains and solubles (DGS). Some plants in the sample produced modified wet distillers grains and solubles (MWDGS), produced by drying wet distillers grains (WDGS, essentially centrifuge cake, with about $70 \%$ moisture) and then adding solubles to bring the moisture content to about $50-55 \%$. Most plants also produced 
dry distillers grains and solubles (DDGS) by further drying to about $10 \%$ moisture. While it is costly to do this additional drying, the product is more storable and transportable, and thus more valuable. On average among survey plants, $54 \%$ of byproduct was sold as DDGS, but this ranged from one plant that sold absolutely no byproduct as DDGS to another plant that sold nearly all byproduct (97\%) as DDGS.

Finally, Table 1 briefly reports plant marketing techniques. In purchasing feedstock, nearly all plants (5) purchased most corn via direct customer contracts. In selling ethanol, nearly all plants (5 of 7) employed third parties or agents. Byproduct marketing techniques varied more across plants. Marketing of DDGS was split fairly evenly between spot markets and third parties/agents. Even more variability was observed in marketing methods for MWDGS, where no one marketing strategy (spot market, customer contract, or third party/agent) prevailed. Most if not all plants participated in futures and option markets for either products or inputs or both, but we did not inquire into the details of these transactions because of the difficulty of quantifying the kinds and extent of these activities. Quarterly output and input prices reported in this study are net prices realized from the combination of commodity transactions and futures transactions, as reported by the plant managers.

\section{Technical efficiency}

Because input prices can fluctuate substantially, any given estimate of production cost can become quickly out of date.
What will persist are technical efficiencies - output-input ratios. Here, we present technical efficiency coefficients for this sample of plants, and contrast them with other estimates currently in use in the literature on ethanol plant performance.

\subsection{Technical efficiencies across surveyed plants}

Table 2 presents the technical efficiencies in terms of input requirements per gallon of denatured ethanol, and outputs of denatured ethanol and DGS byproduct (all distillers grains and solubles, measured in pounds of dry matter) per bushel of corn. We report the average input efficiency coefficients across all seven plants along with the average of the two plants with lowest processing costs and the two with the highest processing costs. We report output efficiency in terms of gallons of ethanol and pounds of byproduct dry matter per bushel of corn, with low- and high-performing plants determined according to revenue per bushel of corn feedstock.

Electricity requirement was dispersed around an average of $0.570 \mathrm{kWh}$ per gallon of ethanol; the low-cost plants required about 2\% less, whereas the high-cost plants required $2 \%$ more. Average natural gas requirement was $0.026 \mathrm{MMBTU} / \mathrm{gal}$ of ethanol, with low- and high-cost plants each varying about $8 \%$ from that level.

Output per unit of feedstock, on the other hand, varied less than $1 \%$ between the best, worst and average plant. This was true whether we considered output of denatured ethanol (averaging $2.87 \mathrm{gal} / \mathrm{bu}$ ) or of dry matter in DGS (averaging 14.75 lbs/bu.) The coefficient of variation across plants (standard

Table 1. Characteristics of the seven surveyed plants.

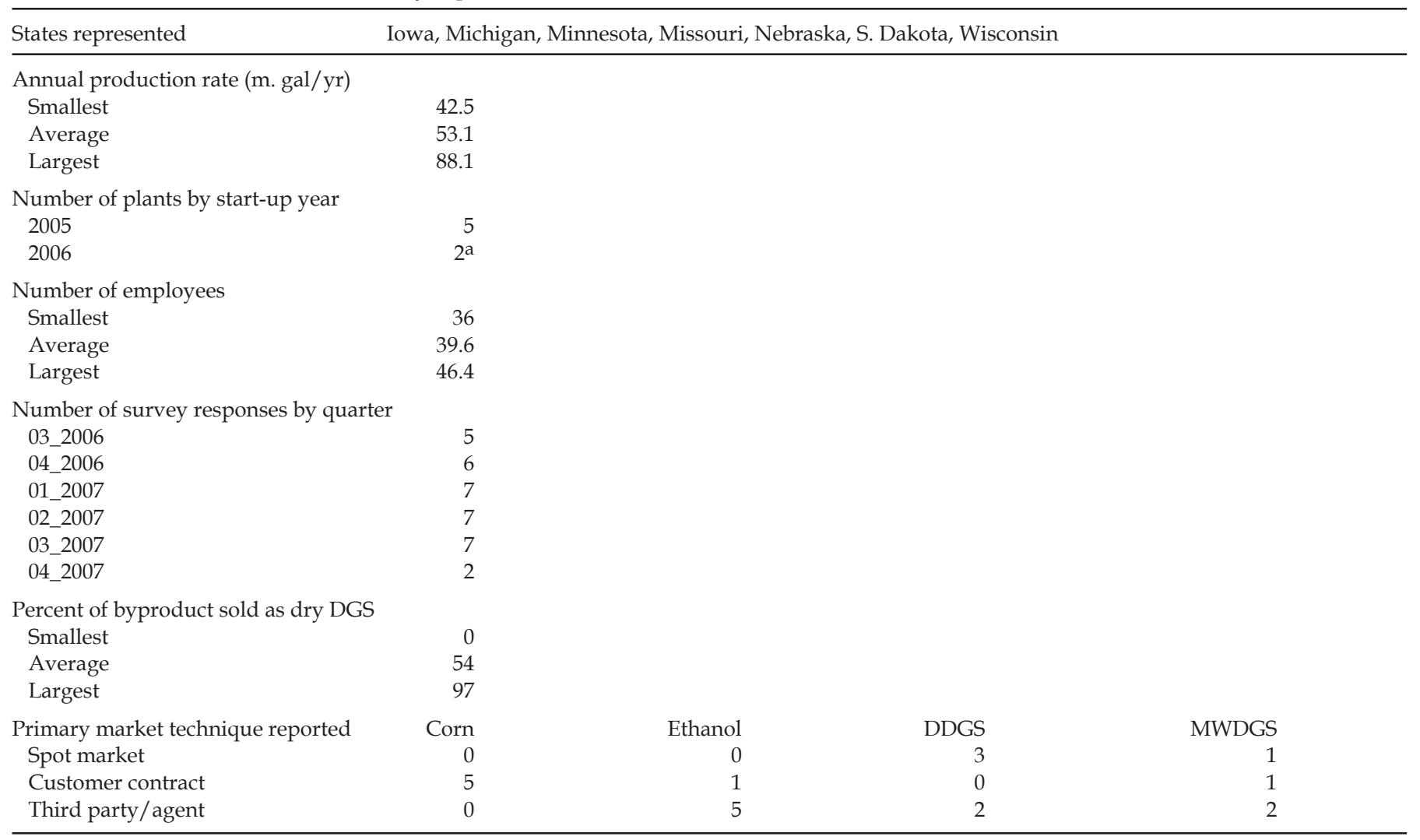

a. One of these plants was originally constructed prior to 2004, but was updated and expanded in 2006. 
deviation divided by mean) for both coefficients was small: 0.036 for output of DGS and 0.024 for output of ethanol. Differences across firms in total revenue per bushel, which is our output ranking criterion, were apparently more a matter of differences in prices than in technical coefficients.

\subsection{Technical efficiencies of surveyed plants versus previous estimates}

The plants in our sample are substantially more technically efficient than other recent sources attribute to the industry. Table 3 summarizes these comparisons.

The studies by McAloon et al. (2000), and Kwiatkowski et al. (2006) are original process engineering economic studies. They reveal a considerable improvement in plant efficiency between 2000 and 2006, at least as that is understood from the engineering economic perspective. Compared to the average of our sample plants, Kwiatkowski et al. underestimate electricity requirements by $7 \%$, but overestimate natural gas requirements by $31 \%$. The Shapouri and Gallagher (2005) report was based on a USDA-sponsored survey of plants for the year 2002. Those plants used twice as much electricity and a third more natural gas compared to current plants, while at the same time extracted $6 \%$ less ethanol (but leaving $8 \%$ more DGS.)

Natural gas usage, which represents nearly half of sample plants' processing costs, depends on the extent to which DGS is dried. Several of the studies summarized in Table 3 assumed that all distillers grains were sold as DDGS (McAloon et al., Pimental and Patzek, Kwiatkowski, Eidman and Pleven and Mueller), thus increasing estimated natural gas usage relative to the plants in this sample, which sold only $54 \%$ of byproduct as DDGS. Wang et al., estimate .0333 MMBTU/gal for DDGS plants, .0218 for WDGS plants, which, when weighted by the share dried in our sample, yields results essentially the same as realized in our sample plants.

The studies by Wang et al. (2007), and Plevin and Mueller (2008), are based on spreadsheet models of the industry (GREET and BEACCON, respectively), for which sources of efficiency estimates are not readily available. The studies by Pimentel and Patzek (2005), and by Eidman (2007), also do not clearly indicate the source of estimates.

The most recent of all these studies seem to exhibit a consensus that requirements for both electricity and natural gas are considerably higher than our sample plants used, and that the yield of ethanol is slightly lower, leaving DGS yields slightly higher.

\section{Cost efficiency and shutdown prices}

A central objective of the project supporting this research was to evaluate the financial viability of the corn ethanol industry. In this section, we construct ethanol production budgets and describe financial performance across plants and through the six-quarter sampling period. From this information we identify combinations of corn and ethanol prices that result in operating losses, and would thus cause plants to shut down. Some expenditure categories were reported in dollar amounts, thus we could not identify quantities used and we could not report technical efficiencies for those categories.

Table 2. Technical efficiency of seven dry-grind corn ethanol plants in this survey.

\begin{tabular}{lllll}
\hline Item & \multicolumn{1}{l}{ Units } & Group averages & & \\
\hline Input requirements per gallon of denatured ethanol: & $\mathrm{kWh} / \mathrm{gal}$ & 0.559 & All plants & \multicolumn{1}{c}{ Two high-cost plants } \\
$\quad$ Electricity & $\mathrm{MMBTU} / \mathrm{gal}$ & 0.0241 & 0.570 & 0.581 \\
$\quad$ Natural gas & & Two high-revenue plants & All plants & 0.0282 \\
Outputs per bushel of corn: & $\mathrm{gal} / \mathrm{bu}$ & 2.85 & 2.86 & 2.86 \\
Denatured ethanol & $\mathrm{lbs} \mathrm{DM} / \mathrm{bu}$ & 14.8 & 14.9 & 14.8 \\
DGS (distillers grains and solubles) & & & \\
\hline
\end{tabular}

Table 3. Technical efficiency of surveyed plants versus previous estimates. ${ }^{a}$

\begin{tabular}{|c|c|c|c|c|c|c|c|c|c|}
\hline Item & Units & $\begin{array}{l}\text { Plants } \\
\text { in this } \\
\text { survey }\end{array}$ & $\begin{array}{l}\text { McAloon } \\
\text { et al. } \\
(2000)\end{array}$ & $\begin{array}{l}\text { Shapouri and } \\
\text { Gallagher (2005) } \\
\text { (2002 survey) }\end{array}$ & $\begin{array}{l}\text { Pimentel } \\
\text { and Patzek } \\
(2005)\end{array}$ & $\begin{array}{l}\text { Kwiatkowski } \\
\text { et al. (2006) }\end{array}$ & $\begin{array}{l}\text { Eidman } \\
\text { (2007) }\end{array}$ & $\begin{array}{l}\text { Wang } \\
\text { et al. } \\
(2007)\end{array}$ & $\begin{array}{l}\text { Plevin and } \\
\text { Mueller } \\
(2008)\end{array}$ \\
\hline \multicolumn{10}{|c|}{ Input requirements per gallon of denatured ethanol } \\
\hline \multirow[t]{2}{*}{ Electricity } & \multirow[t]{2}{*}{$\mathrm{kWh} / \mathrm{gal}$} & \multirow[t]{2}{*}{0.570} & 0.650 & 1.190 & 1.486 & 0.532 & 0.750 & 0.750 & 0.750 \\
\hline & & & $114 \%$ & $209 \%$ & $261 \%$ & $93 \%$ & $132 \%$ & $132 \%$ & $132 \%$ \\
\hline \multirow[t]{2}{*}{ Natural gas } & \multirow[t]{2}{*}{ MMBTU/gal } & \multirow[t]{2}{*}{0.0263} & 0.0419 & 0.0348 & 0.0383 & 0.0345 & 0.0340 & $0.0278^{b}$ & 0.0323 \\
\hline & & & $159 \%$ & $132 \%$ & $145 \%$ & $131 \%$ & $129 \%$ & $106 \%$ & $123 \%$ \\
\hline \multicolumn{10}{|c|}{ Outputs per bushel of corn } \\
\hline \multirow{2}{*}{$\begin{array}{l}\text { Denatured } \\
\text { ethanol }\end{array}$} & \multirow[t]{2}{*}{$\mathrm{gal} / \mathrm{bu}$} & \multirow[t]{2}{*}{2.86} & 2.85 & 2.68 & 2.29 & 2.83 & 2.75 & & 2.80 \\
\hline & & & $99 \%$ & $94 \%$ & $80 \%$ & $99 \%$ & $96 \%$ & & $98 \%$ \\
\hline \multirow{2}{*}{$\begin{array}{l}\text { DGS (distillers } \\
\text { grains and } \\
\text { solubles) }\end{array}$} & \multirow[t]{2}{*}{ lbs DM/bu } & \multirow[t]{2}{*}{14.9} & 16.4 & 16.2 & 16.6 & 16.7 & 16.2 & & 16.1 \\
\hline & & & $110 \%$ & $108 \%$ & $112 \%$ & $112 \%$ & $109 \%$ & & $108 \%$ \\
\hline
\end{tabular}

a. Percentages indicate coefficient estimate relative to surveyed plants.

b. Average Wang results for DDGS and WDGS, weighted by shares in this study, 54\% DDGS, 46\% WDGS. 


\subsection{Average reported operating costs and revenues}

In Table 4, we present average operating costs at the surveyed plants. Operating cost was broken down into two categories: processing cost and net feedstock cost (cost of corn feedstock minus revenues from DGS.) Processing costs consist of all operating expenditures other than feedstock cost. Capital costs were not reported in the survey, are not included in the budget. To provide an idea of dispersion of prices and costs within the industry, we also present average budget information for the two plants with the highest processing costs and the two with the lowest processing costs.

In the previous section, we noted that there was little dispersion of technical coefficients across firms. Yet here we note that processing costs vary by at least $\$ 0.16 /$ gal, from $\$ 0.37 /$ gal for the two low-cost firms to $\$ 0.53 /$ gal for the high-cost firms, a range equal to $36 \%$ of the average cost. Electricity cost per gallon varies by $24 \%$ of the average and natural gas by $22 \%$ of average. A cost range of $\$ 0.06 /$ gal arose from either the technical coefficients or prices paid for chemicals, yeasts, etc., which together comprise half of the processing cost.

Two other processing cost items that varied the most between high-cost and low-cost plants are labor/management costs and miscellaneous costs. In follow-up discussions with respondents, we learned that much of the labor/management variability was due to payments of bonuses, which were reported jointly with normal salary and wage payments. Given that net revenues were quite high during the first two quarters of this survey, bonuses were probably quite high, rendering these estimates of labor/ management commensurately high. Miscellaneous costs reported by at least one plant include contract payments for consulting, whereas others do not, and may not have had such expenditures. In addition, it is quite possible that the survey period miscellaneous costs included two semi-annual payments for services at some plants, but only one such payment at other plants. However, we have no way to determine exactly why miscellaneous expenses varied so much across plants.

Net feedstock costs, on the other hand, showed a spread of only $\$ 0.05 /$ gal, or about $6 \%$, determined mostly by differences in corn price that varied by about $8 \%$, and differences in byproduct price that varied by about $20 \%$ of average prices. Differences in prices (corn, ethanol and byproduct) reflect spatial differences in spot prices, some temporal differences due to periods reported, and some managerial differences due to marketing skills and futures market transactions. In a follow- up study, we will attempt to learn what we can about the importance of these factors in explaining price differences. Finally, net operating costs varied $\$ 0.11 /$ gal between low-cost and high-cost firms, about $8 \%$ of the average cost of $\$ 1.29 /$ gal.

Average prices received for ethanol of $\$ 1.95 /$ gal were augmented slightly by an average of $\$ 0.03 /$ gal in production subsidies, leaving average net operating returns of $\$ 0.90, \$ 0.69$ and $\$ 0.62$ /gal for the three groups of firms. Operating subsidies consisted of the Federal Small Ethanol Producer Tax Credit (plants producing 60 million gallons per year or less are eligible for $\$ 0.10 /$ gal on the first 15 million gallons of production) and state production subsidies for which two of the plants qualified. The major federal subsidy during this period was the Volumetric Ethanol Excise Tax Credit (VEETC) of \$0.51/gal, but as this was paid to blenders of ethanol and gasoline rather than to the plants, it affects the plants through higher prices for ethanol than they would otherwise have received.

Clearly the average net operating returns of $\$ 0.69 /$ gal during this period were adequate to keep the plants in production, and provide substantial returns to capital. A view of net returns over the six-quarter operating period, however (Figure 1) reveals that the average operating margin declined from $\$ 1.11$ in the third quarter of 2006 to $\$ 0.43$ in the third quarter of 2007. Are these operating costs sufficient to cover capital costs? While our survey did not gather any information about capital costs, construction costs are in the vicinity of $\$ 1.80 / \mathrm{gal}$ of annual capacity. For a life of 10 years at a $15 \%$ rate of interest, amortization of that investment amounts to $\$ 0.36 /$ gal. Hence, even at the lowest average quarterly operating return of $\$ 0.43 /$ gal, the average plant would make sufficient earnings to cover capital cost of this magnitude. (Capital leveraged at higher interest rates than $15 \%$, or over shorter periods than 10 years could create cash-flow problems if debt repayment expenses exceeded the $\$ 0.36 /$ gal/year amortization.)

\subsection{Reported costs of surveyed plants versus previous estimates}

As with technical efficiencies, we compared the average costs from our survey to some previously published estimates, namely those of Shapouri and Gallagher (2005), Kwiatkowski et al. (2006), Eidman (2007), and Plevin and Mueller (2008, citing the spreadsheet program, BEACCON). The results of this comparison are shown in Table 5. For both processing and feedstock costs, our survey results lie within the range of previous estimates. For processing cost alone, the previous esti-

Table 4. Average reported operating costs and revenues at seven surveyed ethanol plants.

\begin{tabular}{|c|c|c|c|c|c|c|c|}
\hline \multirow[t]{2}{*}{ Item } & \multirow[t]{2}{*}{ Units } & \multicolumn{3}{|l|}{ Price/unit } & \multicolumn{3}{|c|}{ Input cost per gallon of denatured ethanol } \\
\hline & & Two low-cost plants & All plants & Two high-cost plants & Two low-cost plants & All plants & Two high-cost plants \\
\hline Electricity & $\mathrm{kWh}$ & 0.037 & 0.044 & 0.047 & 0.021 & 0.025 & 0.027 \\
\hline Natural gas & MMBTU & 6.42 & 7.20 & 6.99 & 0.155 & 0.190 & 0.197 \\
\hline Denaturant & & & & & 0.067 & 0.070 & 0.078 \\
\hline Enzymes, yeasts, chemicals & & & & & 0.058 & 0.063 & 0.062 \\
\hline Labor, mgt (incl. bonuses) & & & & & 0.033 & 0.051 & 0.066 \\
\hline Maintenance and repairs & & & & & 0.021 & 0.019 & 0.020 \\
\hline Misc - water, taxes, fees, ins, ... & & & & & 0.014 & 0.037 & 0.081 \\
\hline Total processing costs & & & & & 0.370 & 0.454 & 0.533 \\
\hline Feedstock cost (corn) & bu & 3.23 & 3.04 & 2.98 & 1.136 & 1.063 & 1.042 \\
\hline Byproduct (distillers grains) & lbs dry matter & r 0.051 & 0.044 & 0.042 & -0.265 & -0.229 & -0.224 \\
\hline Net feedstock costs & & & & & 0.871 & 0.834 & 0.819 \\
\hline Net operating costs & & & & & 1.240 & 1.288 & 1.352 \\
\hline Ethanol revenue & & & & & 2.089 & 1.951 & 1.941 \\
\hline Operating subsidies & & & & & 0.047 & 0.031 & 0.029 \\
\hline Return over operating cost & & & & & 0.895 & 0.694 & 0.617 \\
\hline
\end{tabular}




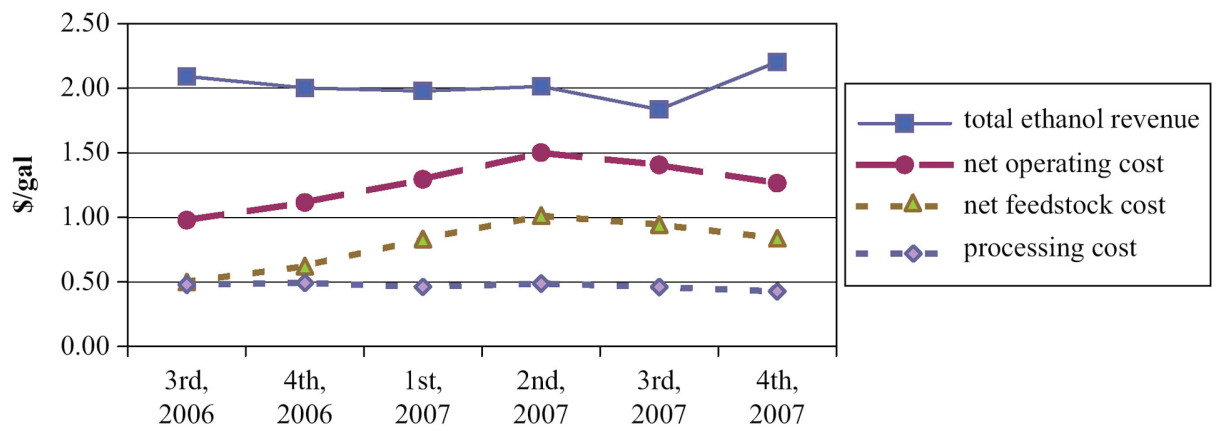

Figure 1. Average quarterly operating costs and revenue at survey plants.

mates ranged from $\$ 0.41 /$ gal (Shapouri and Gallagher (2005), for the operating year 2002) to $\$ 0.59 /$ gal (Eidman, 2007); our survey reports a processing cost of $\$ 0.45 /$ gal. Feedstock cost estimates have been more variable as corn prices have risen in recent years. The previous estimates ranged widely from $\$ 0.48$ /gal (Kwiatkowski et al., 2006) to $\$ 1.60 /$ gal (Plevin and Mueller, 2008); our survey reports a net feedstock cost of $\$ 0.83 /$ gal.

\subsection{Shutdown prices for corn and ethanol at surveyed plants}

If the price for ethanol falls below a plant's operating cost, the plant cannot continue operating for very long. The shutdown of a single plant can have grave consequences for the community in which the plant is located, particularly so because most corn ethanol plants are located in small communities.We are therefore interested in circumstances that might lead to shutdowns, and since ethanol price and corn price are the two most significant prices affecting economic performance, we construct shutdown price lines as shown in Figure 2.

Shutdown of a plant would presumably occur when ethanol price falls below operating cost per gallon. In the case of the average of plants in our sample, the prices that would trigger shutdown are

$$
P_{e}=0.454+\frac{1}{2.86} P_{c}-5.21 P_{D G S}-\text { Subsidy }
$$

where $P_{e}$ is the price of a gallon of denatured ethanol, 0.454 is the average processing cost, 2.86 is the average yield of denatured ethanol per bushel of corn, $P_{c}$ is the price of corn, 5.21 is the number of dry matter pounds of DGS per gallon $(14.9 \mathrm{lb} /$ bu divided by $2.86 \mathrm{gal} / \mathrm{bu}), P_{D G S}$ is the price per dry matter pound of DGS, and Subsidy is the average operating subsidy received $(\$ 0.03 / \mathrm{gal})$. The price of DGS is closely related to the price of corn (they are substitute feeds), so we approximate it from corn price as

$$
P_{D G S}=\left(\frac{\bar{P}_{D G S}}{\bar{P}_{c}}\right) P_{c}=0.0145 P_{c}
$$

where overbars represent the average prices from our sample. Substituting this into (1) and collecting terms yields the breakeven operating relationship between ethanol and corn prices

$$
P_{e}=0.424+0.2742 P_{c}
$$

Changes in processing costs shift the intercept, and changes in the relative prices of DGS and corn would alter the slope.

Plotted with these curves in Figure 2 are all the quarterly price combinations reported by the plants in the survey. With the exception of one plant for one quarter, these 34 points are scattered above the breakeven lines, confirming that all plants ran an operating surplus in virtually all quarters during this period. The scatter of points, however, offers some sense of variability in corn and ethanol prices among plants and across

Table 5. Surveyed plant operating costs compared with other estimates.

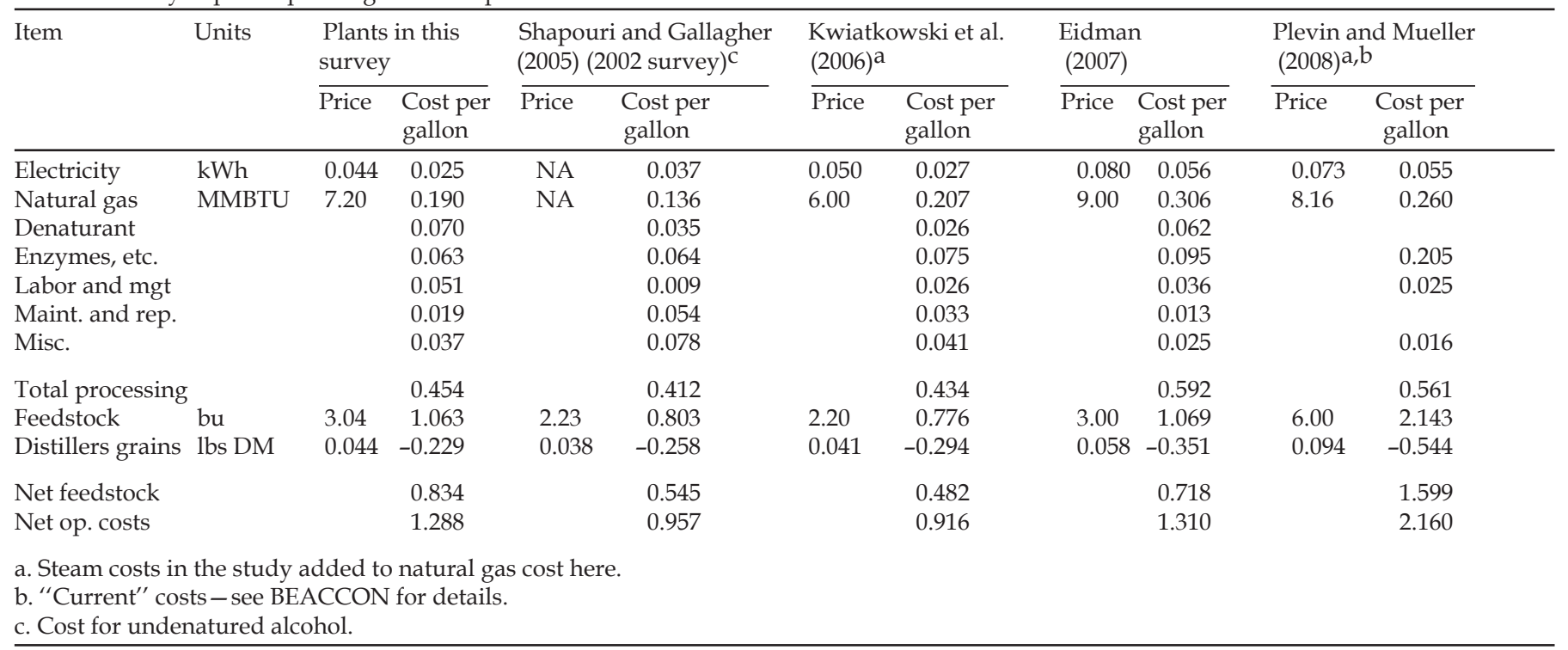




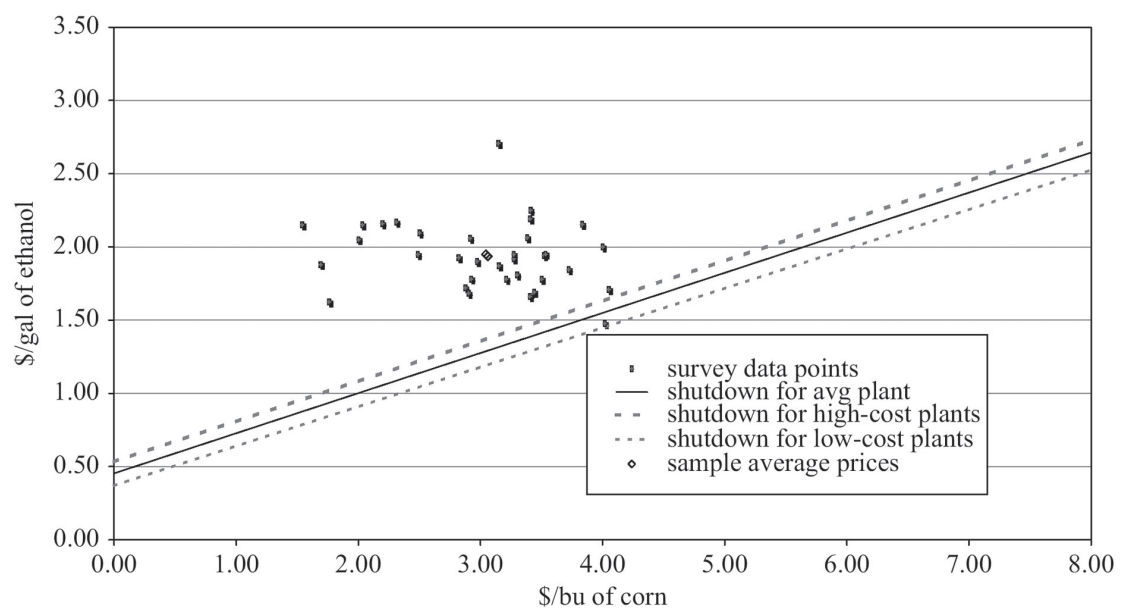

Figure 2. Shutdown prices for corn and ethanol at surveyed plants.

quarters for firms in the industry. This variability arises from spatial and temporal variability in spot prices, but also because these firms utilized forward pricing and hedging strategies in both the corn and ethanol markets. These marketing practices resulted in considerable variation in net prices paid for corn and received for ethanol (which are the prices reported in this study), relative both to spot market prices and to average prices experienced by all firms in a given quarter.

\section{Cost of drying distillers grains}

As discussed earlier, and summarized in Table 1, some plants sold nearly all their byproduct as modified wet distillers grains and solubles, a product with $55 \%$ moisture, while others sold nearly all their byproduct as DDGS (dried distillers grains and solubles), a product with $10 \%$ moisture. MDGS is created by eliminating water from the distillage using centrifuges or filters, while additional drying to sell as DDGS requires heat processes that use additional natural gas.

We would, thus expect plants selling DDGS to use more natural gas than those that sell MWDGS. To estimate the amount of additional natural gas required, we used the 34 quarterly survey reports as observations, and regressed total MMBTU/ton of DGS dry matter on the fraction of byproduct sold as DDGS. Data and results are reported in Figure 3. (Data do not include three quarterly reports from the plant that sold only MWDGS, because the plant was having boiler problems during these quarters, with unusually high natural gas use, even relative to plants that were drying all DGS. When we included these observations, the estimate of MMBTU/ton fell to 2.5, but we felt this estimate did not reasonably represent the experience of plants under normal operating conditions.) The slope of the regression equation, 3.58, is our estimate of the extra MMBTU required to dry one ton of byproduct, dry matter basis, from 55\% moisture (MWDGS) to $10 \%$ moisture (DDGS.) When translated to natural gas per gallon of ethanol produced, drying the byproduct is estimated to increase MMBTU/gal by 0.00933. (Wang et al. (2007) estimate that an additional $0.0115 \mathrm{MMBTU}$ is required.)

As we show in Table 6, at the average survey price of $\$ 7.20 / \mathrm{MMBTU}$, this estimate implies an average drying cost of $\$ 25.80 /$ ton of dry matter in DGS, or equivalently, $\$ 0.0672$ / gal of ethanol for which the associated byproduct is dried to be sold as DDGS. There may be other variable costs associated

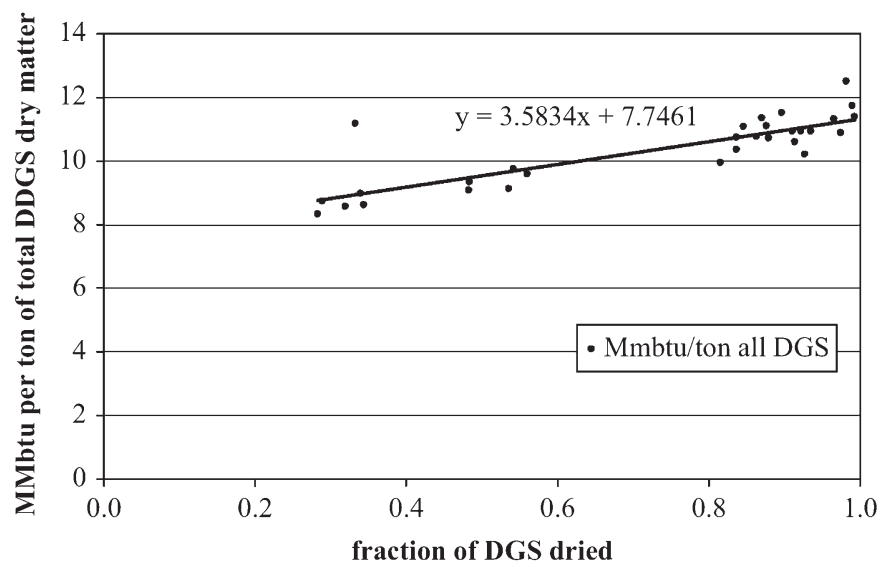

Figure 3. Natural gas vs. fraction of DGS dried.

with additional drying of the byproduct from about $50 \%$ to about $10 \%$, (such as electricity or additional drier capacity), and to that extent, our estimate of the drying cost based on natural gas cost alone is an underestimate of the total drying cost.

\section{Updating costs using a cost function}

To further extend the results of this study to new price regimes in the future, we have constructed an ethanol cost function to allow us to adjust the average cost at these plants to new price levels.

\subsection{A cost function to represent costs for the average firm}

The cost function describes per-gallon operating cost as a linear function in the prices of inputs. For the cost of electricity, for example, the price Pkwh represents the price per kilowatt hour, and the coefficient is simply the average input requirement from Table 2, or 0.57 .

The cost function we develop is

$$
\begin{aligned}
\text { Cost }= & 0.570 P_{k w h}+\left(0.02016+0.0933 f_{d}\right) P_{M M B T U} \\
& +0.000480 P_{E C I}+0.274 P_{\text {corn }}+0.00128 P P I_{\text {eam }}
\end{aligned}
$$

where, Cost represents operating cost per gallon of denatured ethanol; $P_{k w h}$ is the price of electricity per kilowatt hour; $f_{d}$ is the fraction of byproduct sold as DDGS rather than MWDGS; 
$P_{M M B T U}$ is the price of natural gas per MMBTU; $P_{E C I}$ is the Employment Cost Index (series CIS101) from the Bureau of Labor Statistics (http://www.bls.gov/news.release/eci.nr0. $\underline{\mathrm{htm}}) ; P_{\text {corn }}$ is the price of corn per bushel; $P P I_{e a m}$ is the Producer Price Index for the ethyl alcohol manufacturing industry (series PCU325193325193) from the Bureau of Labor Statistics (http://www.bls.gov/data/\#prices).

Coefficients for prices of electricity and natural gas represent quantities per gallon of ethanol, with natural gas requirement adjustable for the fraction of byproduct that is dried $\left(f_{d}\right)$ But coefficients for PECI and PPIeam are implicit quantity indexes calculated by dividing survey sample expenditures on personnel and on all other processing inputs by the sampleperiod average values of the respective price indexes. The coefficient for the price of corn measures the net feedstock quantity - the quantity of corn required per gallon minus the corn-equivalent value of byproduct, with byproduct price set at the average sample value relative to corn.

To adjust operating cost to the level of prices in July, 2008, we utilize the cost function as detailed in Table 7. Column four shows average prices from our survey and column five shows the resulting cost of the respective components in survey average cost of production. Columns five and six adjust to approximate prices as of early July, 2008. The effect of input price increases was to increase the average cost of production from $\$ 1.28 /$ gal in our sample, to $\$ 2.30 /$ gal in July, 2008. The main contributors to this $\$ 1.02 /$ gal cost increase were the net feedstock cost, which increased by $\$ 0.81 /$ gal, and natural gas cost, which increased by $\$ 0.18 /$ gal.

\subsection{Updated shutdown prices and firm performance using the cost function}

We used the cost function with an approximation to July, 2008, prices, to map an updated shutdown curve as represented in Figure 4 by the dashed line. (The solid line repeats the breakeven line presented in Figure 2.) We estimate average July, 2008, ethanol price for our sample of firms at about \$2.42/gal and corn price at $\$ 6.00 / \mathrm{bu}$. With other processing input prices adjusted to mid- 2008 levels, and corn at $\$ 6.00$, estimated operating costs are $\$ 2.30 /$ gal, just $\$ 0.12 /$ gal below ethanol price. Clearly, these prices offer no incentive for further plant investment, and are barely sufficient to keep existing plants in operation.
To allow us to see the dispersion in how our sample plants might have performed in 2008 relative to this new breakeven line, we assumed that each plant would continue to experience the same absolute price deviations from average, and the same technical efficiency, as during the sample period. We thus translated each of the 34 reported quarterly observations (reported in Figure 2) to July, 2008, conditions by adjusting them for the absolute change in average prices that occurred between the quarter being reported and our approximation of July, 2008, prices. These translations give us the predicted performances indicated by the scatter of projected data points indicated in Figure 4.

The financial health of the industry in July, 2008, as depicted in Figure 4, is certainly worse than that during the sample period (Figure 2), and this demonstrates the potential financial precariousness of the industry, even in the presence of the VEETC and state subsidies. Eleven of the 34 predicted outcomes fall below the shutdown line, and another eight or so are very close. Without the VEETC subsidy at $\$ 0.51$ /gal during the sample, ethanol price would presumably be about $\$ 0.50 /$ gal lower, dropping all but one of our constructed outcomes below the shutdown level. Plants could not choose to operate very long at prices below the shutdown line.

\section{Conclusions}

This survey of seven dry grind ethanol plants in seven Midwest states has shown that the corn ethanol industry is substantially more technically efficient than previously estimated. This finding is important for evaluating both the likely greenhouse gas contributions and the economic viability of the industry.

During the period surveyed, 2006-2007, these plants on average received ethanol prices that were about $\$ 0.66 /$ gal above shutdown level, that is, above variable operating costs. While capital costs were not considered in this survey, recent estimates suggest a capital charge of about $\$ 0.35 /$ gal for interest and depreciation, and thus net operating returns during the sample period would have been more than sufficient to induce new plant construction. However, net operating returns fell sharply during the six-quarter reporting period. Furthermore, when we adjusted input prices to the level of July, 2008, estimated average net operating revenue drops to about $\$ 0.12$ / gal, clearly not sufficient to cover capital costs.

Table 6. Estimated cost of drying distillers grains.

\begin{tabular}{llccc}
\hline Unit of production & MMBTU for MWDGS & MMBTU for DDGS & $\begin{array}{c}\text { Extra MMBTU } \\
\text { for DGS drying }\end{array}$ & $\begin{array}{c}\text { Drying cost per unit } \\
\text { at } \$ 7.20 / \text { MMBTU }\end{array}$ \\
\hline $\begin{array}{l}\text { Per ton (dry matter) of DGS } \\
\text { Per gal of ethanol }\end{array}$ & 7.746 & 11.330 & 3.583 & $\$ 25.80$ \\
\hline
\end{tabular}

Table 7. Operating cost function evaluated at sample and projected prices.

\begin{tabular}{|c|c|c|c|c|c|c|}
\hline \multirow[t]{2}{*}{ Cost component } & \multirow[t]{2}{*}{ Price definition } & \multirow[t]{2}{*}{ Cost function coefficient } & \multicolumn{2}{|c|}{ At survey average prices } & \multicolumn{2}{|c|}{ Approximate July, 2008, prices } \\
\hline & & & Price & Component cost & Price & Component cost \\
\hline Electricity & $\$ / \mathrm{kW} \mathrm{h}$ & 0.570 & 0.0437 & 0.025 & 0.0446 & 0.025 \\
\hline Natural gas & \$/MMBTU & 0.02016 & 7.20 & 0.145 & 12.50 & 0.252 \\
\hline Labor and mgt & $\mathrm{P}_{\mathrm{EC}} \mathrm{I}$ & 0.000480 & 105.3 & 0.051 & 108.2 & 0.052 \\
\hline Other & $\mathrm{PPI}_{\text {eam }}^{\mathrm{EC}}$ & 0.001276 & 148.1 & 0.189 & 167.9 & 0.214 \\
\hline Total processing cost per gal & & & & 0.450 & & 0.660 \\
\hline
\end{tabular}




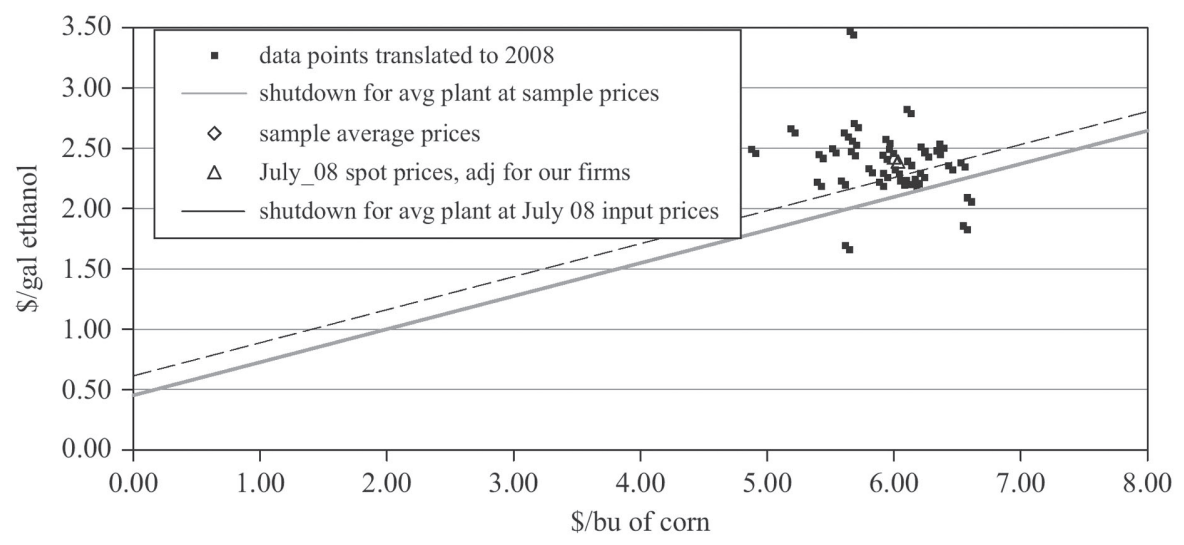

Figure 4. Shutdown corn and ethanol prices, updated to July, 2008, input prices.

The survey revealed substantial variability across firms in financial performance, but relatively small differences in technical efficiency measures. Only one of the 34 quarterly performances reported was near the shutdown level, but when we projected each of the 34 reported quarterly performances to July, 2008, market price conditions, 11 of them would have been operating at or below shutdown levels. If these prices were to persist for a quarter or two, there would no doubt be a number of plants across the industry shutting down, with perhaps severe consequences for their small communities. It is important that this possibility be evident not only to plant owners and managers, but also to community leaders and policy makers.

Direct production subsidies played a minor role in the finances of these plants. Two of the seven plants received no operating subsidies, others were eligible for federal or state subsidies that averaged $\$ 0.03 /$ gal across all plants-significant amounts in the aggregate, but relatively small in determining financial viability of the industry. The most significant subsidy affecting the industry, the federal Volumetric Ethanol Excise Tax Credit (VEETC) of $\$ 0.50 /$ gal is paid to blenders, and thus is reflected in the market price for ethanol. In the absence of VEETC, ethanol price would presumably be $\$ 0.50$ / gal lower, and had that been so, these plants would have averaged only $\$ 0.16$ in net operating returns during the reporting period, or only about half enough to cover capital costs for new plant construction. Under July, 2008 prices, operating revenues would have plummeted to $\$-0.38 /$ gal or so, accompanied surely by widespread plant shutdowns.

In general, we conclude that the corn ethanol industry has better performance characteristics than generally acknowledged, and while it remains viable even under July, 2008, prices, returns would not be sufficient to pay capital costs for new plants, and without VEETC, these prices would not have been sufficient for most of these plants to continue operation.

Acknowledgments - This study was supported by the Agricultural Research Service, University of Nebraska, and USDA regional project NC506.

\section{References}

Eidman, Vernon R., 2007. Ethanol Economics of Dry Mill Plants, Ch3 in Corn-Based Ethanol in Illinois and the US. Department of Agricultural and Consumer Economics, University of Illinois.

Kwiatkowski, Jason R., McAloon, Andrew J., Taylor, Frank, Johnson, David B., 2006. Modeling the process and costs of fuel ethanol production by the corn drygrind process. Industrial Crops and Products 23, 288-296.

McAloon, Andrew, Taylor, Frank, Yee, Winne, 2000. Determining the cost of producing ethanol from corn starch and lignocellulosic feedstocks. National Renewable Energy Laboratory NREL/ TP-580-28893.

Pimentel, David, Patzek, Tad W., 2005. Ethanol production using corn, switchgrass, and wood; biodiesel production using soybean and sunflower. Natural Resources Research 14 (1).

Plevin, R.J., Mueller, S., 2008. The effect of $\mathrm{CO}_{2}$ regulations on the cost of corn ethanol production. Environmental Research Letters 3, 024003.

Shapouri, Hosein, Gallagher, Paul, 2005. USDA's 2002 Ethanol Costof-Production Survey. Agricultural Economic Report no. 841, US Dept. of Agriculture.

Wang, Michael, Wu, May, Huo, Hong, 2007. Life-cycle energy and greenhouse gas emission impacts of different corn ethanol plant types. Environmental Research Letters 2. 